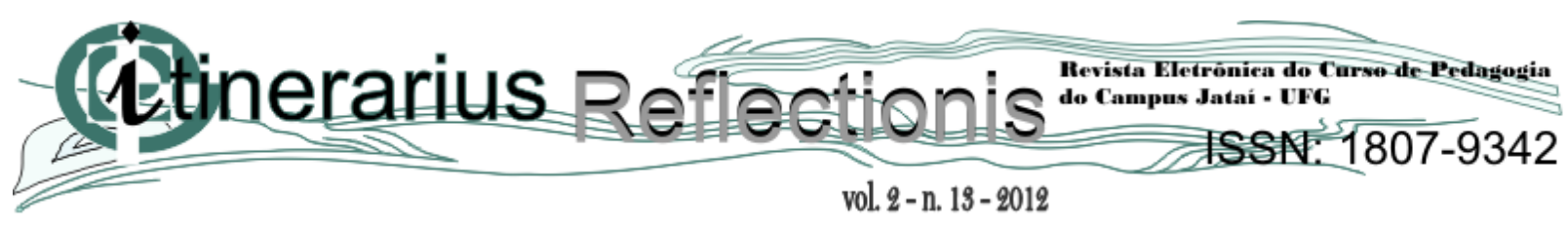

\title{
A MATEMÁTICA NO COTIDIANO DO ENSINO FUNDAMENTAL: A RESOLUÇÃO DE PROBLEMAS COMO EXERCÍCIO DA CIDADANIA
}

\author{
Elenilson de Vargas Fortes - vargasfortes@yahoo.com.br \\ José Elias Domingos Costa Marques - jedomingos27@ yahoo.com.br \\ Instituto Federal de Educação, Ciência e Tecnologia de Goiás (IFG), Câmpus Jataí
}

\begin{abstract}
RESUMO Este artigo descreve uma experiência de monitoria bem sucedida aplicada a estudantes do Ensino Fundamental de uma Escola Estadual de Jataí, Estado de Goiás que funciona nas instalações do Instituto Federal de Educação, Ciência e Tecnologia de Goiás (IFG), Câmpus Jataí, por meio de uma parceria do Estado com o Governo Federal. O projeto teve inicio no começo de 2011, sendo aplicado a três turmas de $8^{\circ}$ ano e duas turmas de $9^{\circ}$ ano e se estende até os dias atuais. O acompanhamento dos alunos ocorreu de forma organizada e planejada em formato de minicurso com carga horária semestral de 45 horas. $\mathrm{O}$ principal objetivo deste trabalho foi mostrar que esta monitoria funcionou como elo no desenvolvimento intelectual, crítico e social do aluno no ambiente escolar bem como na construção da cidadania por meio das atividades desenvolvidas durante a execução do projeto.
\end{abstract}

Palavras-chave: Monitoria. Cidadania. Educação.

ABSTRACT: This article is the result of a monitoring project for the 9th grade students which currently runs at a state school in Jataí, the state of Goiás. The monitoring of the students occurs in an organized and planned way, following the minicourse format with hourly amount of 45 hours per semester. It was shown that actions of this magnitude are important for the student's intellectual and social development at the school environment and the construction of citizenship. Finally, this paper presents the results achieved through monitoring and their contributions in the context of the school students involved in this project.

Key-words: Monitoring. Citizenship. Education.

\section{Introdução}

É muito comum nos dias atuais tanto nos meios de comunicação como no meio acadêmico a falácia 'Deve-se exercer nosso direito de cidadania'. Afinal, por que é tão importante a cidadania? Aliás, o que é cidadania? Este artigo é produto de um projeto de monitoria que foi e ainda se encontra em andamento, desenvolvido com alunos do $8^{\circ}$ e $9^{\circ}$ ano 


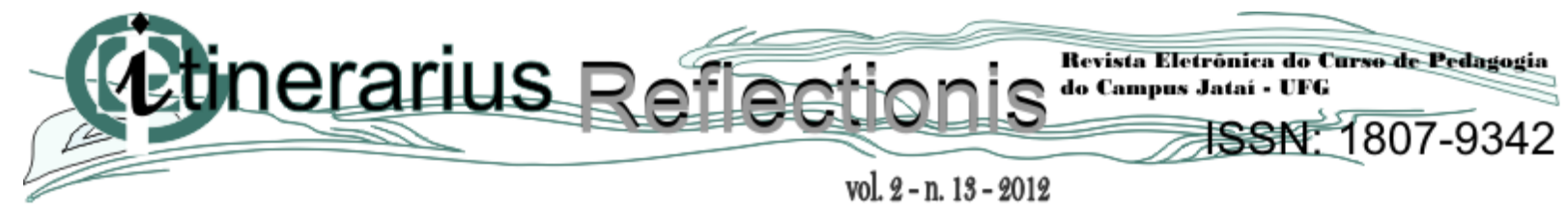

do Ensino Fundamental em uma Escola Pública de Jataí e tem o propósito de responder os questionamentos acima, bem como discutir caminhos que levem os alunos exercerem cidadania por meio do processo ensino-aprendizagem. Desta forma, e com o intuito de discutir tais caminhos, surge seguinte questionamento: como ocorre o aprendizado?

O aprendizado não é desenvolvimento; entretanto, o aprendizado adequadamente
organizado resulta em desenvolvimento mental e põe em movimento vários
processos de desenvolvimento que, de outra forma, seriam impossíveis de acontecer.
Assim, o aprendizado é um aspecto necessário e universal do processo de
desenvolvimento das funções psicológicas culturalmente organizadas e
especificamente humanas, (VYGOTSKY, 1991, p. 101).

Fica claro neste contexto, que toda ação organizada, bem executada e com devido acompanhamento viabiliza processos de aprendizagem que outrora seriam impossíveis de acontecer. Com o intuito de contribuir para a superação dos problemas do ensino tradicional, onde os "professores na maioria das vezes se limitam a transmitir o conteúdo de forma global sem se preocupar com as individualidades, e os alunos se limitam a apenas escutar e memorizar, o que o professor passa, não havendo participação", (SANTOS, 2010), bem como possíveis problemas relacionados à cidadania, onde se restringi os direitos em um país que se pressupõe a igualdade, e o livre-arbítrio, este artigo buscou estimular questionamentos críticos dos alunos em relação à Matemática, procurando se desvincular do ensino tradicional por meio de atividades que estimulem a cidadania. Assim, pretende-se que o discente verifique que a Matemática não se trata apenas de cálculos mecânicos, mas que ela esteja presente em diversas formas no contexto escolar. Para tanto, foram discutidas técnicas de ensino que estimulem o aluno à participação ativa na construção do conhecimento matemático e da cidadania (ver seção Descrição das Atividades). Este trabalho mostrou ações organizadas que têm um objetivo em comum: aprender e desenvolver habilidades em matemática. Além disso, focou-se no tema cidadania e suas aplicações no contexto escolar segundo a visão de pesquisadores tais como Villela (2008), Mendonça (2006), Dallari (1998), Pinsky (2003), Santos (1997) dentre outros, mostrando que definitivamente educação e cidadania devem compartilhar de objetivos comuns para alcançar bons resultados no processo ensinoaprendizagem.

De uma forma mais específica, este artigo buscou: 


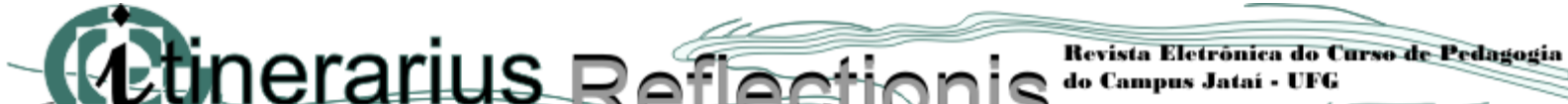 $\Leftrightarrow$ L \\ vol. $2-$ n. $13-2012$

- propor a melhoria da qualidade de ensino em Matemática no Nível

Fundamental e despertar o interesse e o gosto pelo estudo da Matemática;

- estimular os alunos a estudar pelos livros, instigar o questionamento crítico a cerca dos conhecimentos adquiridos e estimular o senso de ajuda mútua, cooperação e disciplina entre os alunos;

- proporcionar aos alunos conhecimentos de teoria e prática da Matemática, indispensáveis ao exercício da cidadania, como por exemplo entender e usar as operações fundamentais e, assim, contribuir para a sua integração na sociedade.

A metodologia de pesquisa utilizada neste trabalho foi o "Estudo de Caso". Segundo Ponte (2006, p. 03) tais estudos "na Educação Matemática" são cada vez mais empregados, uma vez que pesquisas envolvendo estudos de caso são utilizadas para investigar "questões de aprendizagem dos alunos bem como do conhecimento e das práticas profissionais de professores, programas de formação inicial e contínua de professores, projetos de inovação curricular, novos currículos, etc" (PONTE, 2006, p. 03).

Por outro lado, Gil (1999, p. 73), também destaca as várias finalidades do estudo de caso, dentre elas destaca-se:

a) explorar situações da vida real cujos limites não estão claramente definidos;

b) descrever a situação do contexto em que está sendo feita determinada investigação;

c) explicar as variáveis causais de determinado fenômeno em situações muito complexas que não possibilitam a utilização de levantamentos e experimentos.

Além disso, Ponte (2006, p. 02) descreve que o estudo de caso

É uma investigação que se assume como particularística, isto é, que se debruça deliberadamente sobre uma situação específica que se supõe ser única ou especial, pelo menos em certos aspectos, procurando descobrir a que há nela de mais essencial e característico e, desse modo, contribuir para a compreensão global de um certo fenômeno de interesse.

Assim pode-se afirmar que este método atendeu aos anseios deste trabalho, já que neste artigo em particular, estudou-se uma "situação específica" envolvendo uma monitoria para turmas do Ensino Fundamental, onde se investigou, descreveu e explicou um caso particular de forma que se pode "contribuir para a compreensão global de certo fenômeno de interesse", (PONTE, 2006, p. 02). 


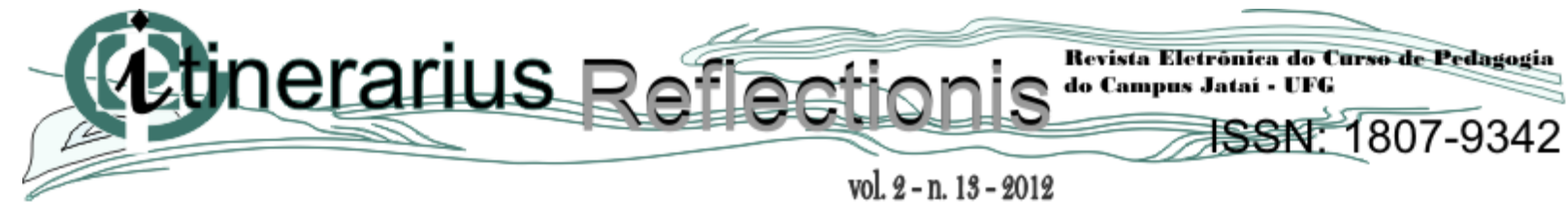

Este trabalho está disposto em partes, sendo: primeiro, dissertou-se sobre a Educação e Cidadania, onde se traçou um paralelo entre ambas as partes. Mostrou-se que através da Educação o aluno pode desenvolver habilidades para o exercício da Cidadania.

Na próxima seção tratou-se de apresentar e esclarecer o que é a "Avaliação Diagnóstica". Além disso, foram mostrados quais são os principais motivos que levaram a realização do projeto de monitoria.

Na seção "Descrição das Atividades" delimitou-se a mostrar como funciona o projeto, pois foi através deste que foi possível escrever este artigo. Por fim, foram apresentados os "Resultados Obtidos", onde se expõe dados relevantes acerca do projeto que foi e está sendo executado e por último as "Considerações Finais".

\section{Educação e Cidadania}

Pensar nas questões que envolvem o conceito de cidadania constitui invariavelmente na necessidade de um retrospecto analítico no âmbito da política já pensada na Grécia Antiga, ante às análises aristotélicas sobre a definição e o papel do "ser cidadão". A relação entre cidadania e participar era condição de existência da primeira, como alicerce para a construção de um ideal coletivo (VILLELA, 2008).

Mendonça (2006) afirma que o conceito de cidadania está longe de ser uma categoria fechada, tendo seu significado sucessivamente transformado ao longo da história, onde cada comunidade constrói pra si, tanto uma representação do que sejam os direitos e deveres dos seus membros, quanto às práticas legítimas para seu exercício.

A polissemia do conceito não retira da sua essência a condição histórica da luta da humanidade pelos seus direitos. Se na Roma Antiga, por exemplo, a ideia de cidadania vinculava-se com a capacidade (mesmo que restrita aos "homens livres") para exercer direitos políticos e civis (DALLARI, 1998), essencialmente, hoje, transpõem-se esta ideia chave pensando nas condições de práticas cidadãs como a total capacidade de exercício dos direitos políticos, civis e sociais.

A definição de Jaime Pinsky (2003, p. 09) sintetiza de forma lúcida tanto a amplitude como a importância do ethos de ser cidadão quando afirma que: 


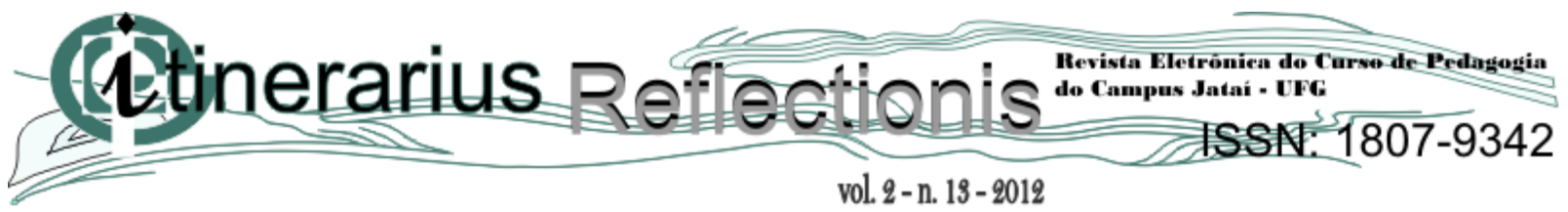

Ser cidadão é ter direito à vida, à liberdade, à propriedade, à igualdade perante a lei: é, em resumo, ter direitos civis. É também participar no destino da sociedade, votar, ser votado, ter direitos políticos. Os direitos civis e políticos não asseguram a democracia sem os direitos sociais, aqueles que garantem a participação do indivíduo na riqueza coletiva: o direito à educação, ao trabalho, ao salário justo, à saúde, a uma velhice tranqüila. Exercer a cidadania plena é ter direitos civis, políticos e sociais.

O direito à educação, apontando por Pinsky (2003) como uma das condições para a efetiva consolidação das práticas dos direitos civis, deve ser pensado não somente no sentido do acesso ao ambiente escolar institucionalizado, mas também a práticas efetivas de conscientização e formação crítica dentro desta esfera da educação formal.

A conceituação do termo cidadania, e sua consequente execução legal, não pormenorizam a situação de marginalidade dos direitos, na sua efetiva aplicação como instrumento para garantir a plena consolidação dos princípios de cidadania. As conquistas sociais refletem uma conquista de direito, que por si requer um longo debate acerca da conjuntura de efetiva aplicabilidade e isonomia dos reais princípios apresentados. Não é difícil pensar, em extrema afinidade com a ideia de Santos (1997), na ideia de cidadania mutilada, visível ante as dificuldades de inserção do indivíduo no rol de oportunidades sociais, como por exemplo, práticas de lazer, emprego digno e igualdade de gênero.

O Brasil, conforme aponta Carvalho (2002), vinculou-se com a consolidação democrática dentro de um contexto (caminho) bastante tortuoso, em tese motivado por uma formação educacional, manuseada pelas faltas de políticas públicas que o Brasil viveu durante décadas no passado e real acesso da população à educação formal. Do longo período de escravidão às recentes dificuldades de inclusão escolar efetiva, gerações inteiras sobraram na possibilidade de se pensar em cidadãos com maior possibilidade de lutar pelos seus direitos.

Neste sentido, a escola atual funciona como um catalisador de potenciais mudanças. Para além de um importante instrumento na transmissão do capital cultural, a escola é também o espaço para o resgate de valores como solidariedade, fraternidade e de respeito às diferenças (SIEGEL, 2005). Caberia, portanto, ao Estado a otimização dos recursos para as práticas educativas voltadas justamente para o fomento e o preparo dos alunos para a vida social enquanto 'bons cidadãos'.

Desta forma, se o Estado não mantém padrões dignos de estrutura e mão de obra qualificada para demanda dos alunos nas escolas públicas, os professores, como cidadãos que 


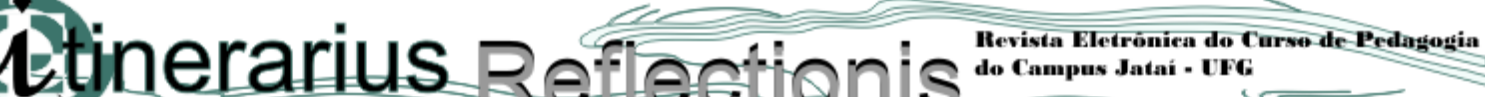

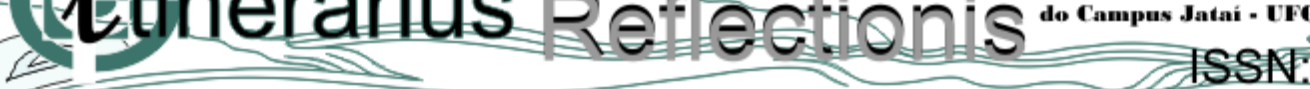 \\ vol. $2-$ n. $13-2012$

estão inseridos no Estado e representam uma minoria crítica em no país, têm o dever de exercer este papel enquanto cidadãos e buscar melhorias ao quadro atual do ensino. Cabe aos professores, desenvolver projetos e ações que propiciem avanços na educação deste país. Atualmente, existem políticas públicas voltadas para melhoria na educação. Gama (2008) afirma que

\begin{abstract}
A política avançou para a educação primária pública, obrigatória e gratuita. Passou por uma política de investimentos em material didático gratuito, merenda escolar gratuita, transporte escolar gratuito e até incentivo em dinheiro para as que as famílias mantivessem os seus filhos matriculados na escola. Veio o combate à repetência, o combate à evasão escolar, os programas de aceleração da educação dos que ficaram à margem da política, o ensino supletivo, e por fim, o ensino semipresencial, pelo rádio (projeto Minerva) e pela televisão (Telecurso). O financiamento da educação pública passou a ser prioridade.
\end{abstract}

Porém, como se encontra a educação em nosso país? De acordo com uma reportagem publicada pela "folha online" tem-se o seguinte relato:

O Brasil manteve a mesma posição do ano passado e ficou no $88^{\circ}$ lugar de 127 países no ranking de educação feito pela Unesco, o braço da ONU para a cultura e educação. Com isso, o país fica entre os de nível "médio" de desenvolvimento na área, atrás de Argentina, Chile e até mesmo Equador e Bolívia, (PINHO, 2011).

Com dados tão alarmantes, fica o seguinte questionamento para reflexão: que contradição o Brasil ser uma das dez maiores economias do mundo se na educação é um dos piores? Neste contexto, fica claro que este país ainda está muito atrasado e muito aquém do desejado por uma população suprimida por um estado que diz 'democrático e popular'.

Em um país com índices tão precários na educação não deve ser difícil de encontrar problemas ou ocorrência de descaso com o ensino. É possível contextualizar o debate com sucessivas reportagens que tratam deste assunto. Como exemplo, Ferreira (2012) relata que "os alunos da rede pública de ensino de Mato Grosso voltam às aulas neste mês de fevereiro em prédios sucateados, com telhados comprometidos e rede elétrica precária. No Estado, cerca de 100 escolas fundadas há mais de 30 anos nunca receberam qualquer tipo de reforma".

Esse é um exemplo dentre aos milhares que se pode citar, porém este não é nosso objetivo, mas sim propor soluções aos problemas já existentes e através de ações simples, auxiliar na aprendizagem de nossos alunos e desenvolver a cidadania. 


\section{(1ttinerarius Reflectionis:}

Este trabalho, sem dúvida, vem na contramão do que se tem proposto para nossas crianças que frequentam escolas. Pretende-se mostrar neste relato que ações com objetivos de melhorar a qualidade da educação e o acesso à cidadania podem gerar resultados, como por exemplo, melhorar a qualidade de ensino em nossas escolas públicas e desenvolver o raciocínio crítico de nossos alunos por meio das atividades desenvolvidas a partir desta monitoria. Os resultados descritos na seção "Resultados Obtidos" colaboraram com esta tese e descrevem uma experiência de trabalho bem sucedida de ensino em matemática em nível fundamental que começou a ser realizada no início do semestre letivo de 2011 e se estende até os dias atuais.

Avaliação Diagnóstica

A Matemática, como as Ciências Naturais e Humanas é de fundamental importância para o desenvolvimento da sociedade em geral e do cidadão. Conforme assinala D’Ambrósio (1990), a importância da matemática deve ser respaldada nas escolas, por ser tratar de um importante instrumento que será útil por toda a vida do cidadão, para o trabalho, e certamente por se tornar parte integrante de nossas raízes culturais, porque nos ajuda a pensar com clareza e a raciocinar melhor. Além disso, a matemática também possui características universais, através de sua construção lógica e formal. Em suma, pode-se certamente afirmar que são muitas as ações afirmativas para alunos com déficit de conhecimentos, tanto no ingresso, como no decorrer de sua formação universitária.

Diante disso, após serem realizadas pesquisas junto a Secretaria Municipal de Educação e Subsecretaria Estadual de Educação de Jataí, através de um levantamento de dados de cada escola localizada neste município, ficou constatado que as unidades de ensino públicas que ofertam vagas em nível Fundamental não possuem e/ou raramente executam atividades específicas para os discentes neste nível de ensino com dificuldade na disciplina de Matemática.

De acordo com o portal do Índice de Desenvolvimento da Educação Básica $(\mathrm{Ideb})^{1}$, percebe-se que o Estado de Goiás teve nota 3,3 no ano de 2005. No ano de 2007 o desempenho do Estado melhorou saltando para 3,4. Por fim, em 2009 a nota foi 3,6. Percebe-

\footnotetext{
${ }^{1}$ Disponível em: <http://sistemasideb.inep.gov.br/resultado/>. Acesso em: 14 jun. 2011.
} 
se ainda que esta Unidade da Federação possui desempenho superior a outros Estados, como por exemplo, Bahia, Alagoas ou Pará. Será que estes indicadores são satisfatórios?

Certamente, este resultado não é interessante para o Estado. Segundo o portal do Ministério da Educação (MEC) "o Ideb foi criado em 2007 para medir a qualidade de cada escola e de cada rede de ensino", (BRASIL, 2011). Portanto, de acordo com dados já apresentados, percebe-se que este o Estado de Goiás não possui rendimento satisfatório neste indicador. Desta forma, a Secretaria da Educação do Estado de Goiás (Seduc) decidiu criar uma metodologia de prova igual a que é utilizada na Prova Brasil, que integra o Ideb, “Avaliação Diagnóstica da Rede Estadual de Ensino”, (GOIÁS, 2011a). De acordo com o portal da Seduc, esta avaliação é aplicada em cada bimestre e um exame no final do ano letivo.

Segundo Moço (2011), a Prova Brasil foi fundamentada nos currículos elencados pelas redes Estaduais e Municipais, pois em nosso país não existe um currículo nacional. Desta forma, uma comissão do MEC analisou todo o material para identificar os pontos em comuns desses currículos. Depois de identificados os pontos convergentes, este estudo deu origem a uma Matriz de Referência, que serve para orientar o trabalho do professor e seus alunos. É importante destacar que a matriz de referência não enfatiza conteúdos, entretanto competências e habilidades. Estas habilidades são dadas por meio de descritores que, em tese, deveriam ser a base para alavancar o conhecimento de nossos alunos.

A “Avaliação Diagnóstica do Estado de Goiás”, (GOIÁS, 2011a), é fundamentada exatamente nesses descritores. A primeira prova foi aplicada no dia 03 de março de 2011 a todos os alunos do $5^{\circ}$ e $9^{\circ}$ anos do Ensino Fundamental e $3^{a}$ série do Ensino Médio nas disciplinas de Matemática e Língua Portuguesa. De acordo com as diretrizes da Secretaria da Educação do Estado de Goiás, seu principal objetivo foi “obter um diagnóstico detalhado das condições de aprendizado nas escolas estaduais para, a partir dele, traçar as ações de melhoria da qualidade da educação no Estado de Goiás", (GOIÁS, 2011b).

Após os resultados obtidos por meio da primeira Avaliação Diagnóstica,

a equipe pedagógica - formada pelo Núcleo de Reforma, Gestão e Resultados, demais superintendências, subsecretarias e unidades educacionais - delimitou ações específicas centradas na formação dos professores nas disciplinas de Português e Matemática; produção de material didático de auxílio ao trabalho do professor; criação de um site para a troca de boas práticas entre professores e de tutores 


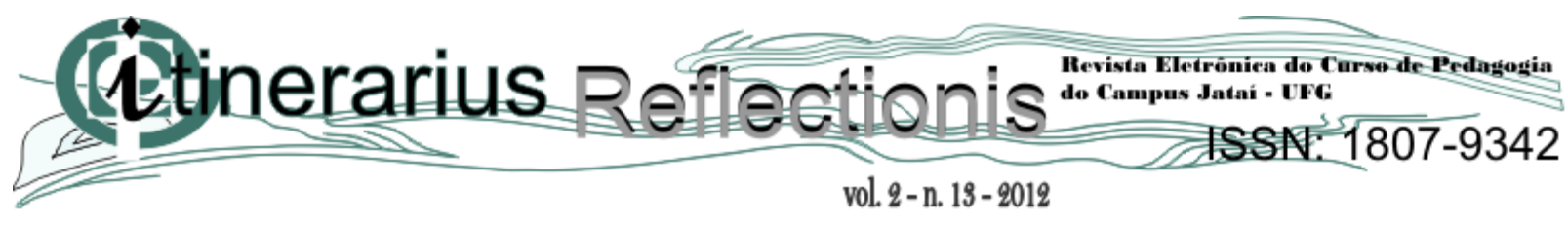

pedagógicos (sugestões de trabalho, atividades, fórum, trocas de experiências, etc); formação do tutor pedagógico, que agora acompanha de perto as escolas; apoio pedagógico intensivo às escolas; e orientação do trabalho de reforço escolar, avaliação contínua e recuperação paralela, (GOIÁS, 2011b).

Evidentemente, que a avaliação diagnóstica tem um objetivo bem claro e definido: "traçar as ações de melhoria da qualidade da educação no Estado de Goiás" através de ações conjuntas como, por exemplo, “formação dos professores nas disciplinas de Português e Matemática; produção de material didático de auxílio ao trabalho do professor; criação de um site para a troca de boas práticas entre professores e de tutores pedagógicos".

Este artigo colabora com os objetivos e metas descritas. O objetivo foi trabalhar com alunos que possuem dificuldades na disciplina de matemática ou para aqueles que queriam aprimorar e desenvolver seus conhecimentos, com pré-disposição a aprofundar os estudos em Matemática (básica e aplicada no seu cotidiano), procurando proporcionar um ambiente fértil para livre exposição de ideias, colaborativo para discussão e resolução de exercícios dos mais diversos bem como o exercício da cidadania.

\section{Descrição das Atividades}

O formato das atividades ocorre em formato de minicurso, com carga horária semestral de 45 horas, quando trinta horas são presenciais e quinze horas não presenciais, sendo possível o seu aproveitamento como atividades complementares. Os encontros ocorreram (ainda ocorrem) semanalmente, cada tutor com sua respectiva turma e com duração mínima de uma hora para cada encontro, totalizando duas horas semanais. Eventualmente, esta carga horária pôde ser modificada, respeitando sempre esse valor mínimo. No que segue, apresenta-se a descrição das atividades.

a) $1^{\mathrm{a}}$ Fase do projeto: Esta fase teve início na $1^{\mathrm{a}}$ e $2^{\mathrm{a}}$ semana do mês de março de 2011. Nesta etapa foram executadas as seguintes tarefas:

- seleção de livros textos;

- elaboração de banco de dados de questões; 


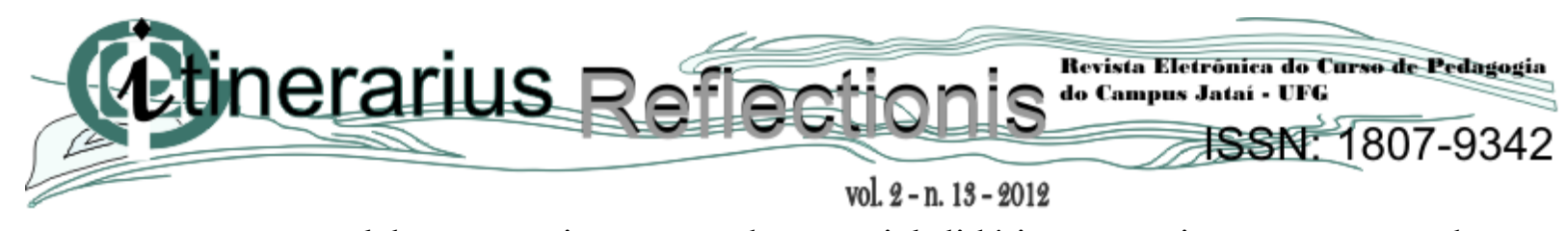

- elaboração e impressão do material didático e reuniões com a coordenação da escola do Ensino Fundamental e executores do projeto para discutir detalhes da execução do mesmo.

b) $2^{a}$ Fase do projeto: esta fase teve início na $3^{a}$ e $4^{a}$ semana de março e se estendeu até 09 de dezembro de 2011 (conforme calendário de férias) da seguinte forma:

- aula 1: apresentações de problemas; estudo teórico dos tópicos da matéria relativa à situação problema e possíveis conteúdos estudados em sala de aula pelos alunos de cada turma (duas turmas);

- aula 2: levantamento de propostas de soluções; estudo das propostas e gabarito da solução do problema.

Vale lembrar que no item (b) as aulas 1 e 2 servem como referências para ministrar suas tutorias em cada semana letiva do semestre, porém, nada impede que algumas mudanças possam ser implantadas, visando à melhoria de cada tutoria. Foram utilizados dois tutores na monitoria, um em cada turma.

As atividades desenvolvidas no projeto tem caráter permanente, pois a proposta vem suprir as mais variadas necessidades dos alunos com atualizações e, portanto, a tutoria continuará sendo realizada nos próximos anos.

Os encontros foram e estão sendo realizados das $18 \mathrm{~h}$ às $19 \mathrm{~h}$ na segunda e quartafeira em sala de aula vaga, laboratório ou sala fixa a definir com a direção local. A seguir, será descrito a estrutura dos encontros em sala de aula, proposta pelo coordenador deste projeto:

- Primeiro momento: propor uma situação problema desafiadora, escolhida pelo professor tutor. A atividade deve tirar o aluno de sua zona de conforto de forma que ele, a princípio, tenha que ativar seus conhecimentos sobre o tema e buscar informações adicionais a de sua formação (até aquele momento);

- Segundo momento: Disponibilizar livros textos didáticos para que os discentes efetuem estudo, contextualizem e executem discussões a cerca da teoria envolvida; 


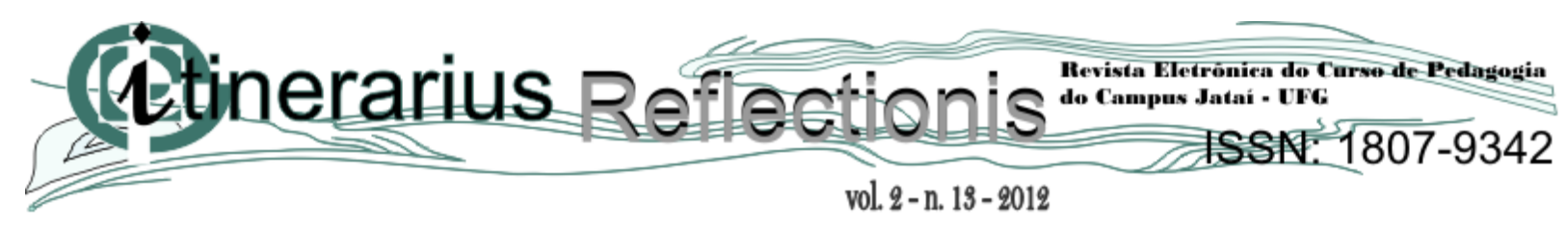

- Terceiro momento: Levantamento das propostas de soluções para o problema. Nesta etapa foram feitas verificações das soluções e os alunos foram motivados a defender seu ponto de vista a respeito de cada resposta apresentada.

Em algum momento as aulas foram desenvolvidas em laboratórios, utilizando-se do espaço físico, dos microcomputadores e de outros recursos que por ventura estavam disponíveis para:

- aulas expositivas;

- leitura e entendimento de textos técnicos;

- $\quad$ apresentação de slides; debates em grupo;

- aulas audiovisuais;

- aulas práticas e pesquisas na internet.

\section{Resultados Obtidos}

Em primeiro lugar, destaca-se que em nenhum momento retirou-se a autoridade do professor em sala de aula, e que o projeto funcionou e ainda funciona como apoio aos alunos que têm dificuldades em matemática e auxilia aqueles que querem desenvolver ainda mais seus conhecimentos e habilidades nesta área. O projeto foi e é executado atualmente em uma Escola Pública Estadual no município de Jataí, atendendo a três turmas de $8^{\circ}$ ano e duas turmas de $9^{\circ}$ ano. Os dados apresentados a seguir incluem apenas as turmas de $9^{\circ}$ ano que fizeram as Avaliações Diagnósticas no ano de 2011. A justificativa para escolha dessa série se baseia no fato de que a Avaliação Diagnóstica se aplica apenas aos "alunos do $5^{\circ}$ e $9^{\circ}$ anos do Ensino Fundamental e $3^{\text {a }}$ série do Ensino Médio", (GOIÁS, 2011b). Além disso, a maioria dos alunos que concluem o Ensino Fundamental nesta escola, a maior parte participa do processo seletivo do IFG, Campus Jataí, para ingressar nos cursos de nível médio (técnico).

O Gráfico 1 apresenta as médias da Turma A, o Gráfico 2 as médias da Turma B no que se refere ao desempenho dos alunos na prova de Matemática. A Turma A possui 39 alunos e apenas dois não compareceram para realizar a avaliação. Já na Turma $B$, todos compareceram à avaliação. 
Diante do exposto nestes dois gráficos ficou evidente um desempenho muito aquém do esperado. Na Turma A, 92\% dos alunos com notas abaixo de 5 e na Turma B um desempenho um pouco melhor, porém não se pode considerar que houve melhorias já que $85 \%$ dos alunos tiveram notas abaixo de 5. Certamente, isso não era esperado e alguma medida deveria ser tomada. Sabendo que a segunda avaliação iria acontecer no dia $1^{\circ}$ de junho de 2011, tinha-se três meses para tentar mudar esta situação (ver os resultados nos Gráficos 3 e 4). Conforme os resultados, não poderiam ser melhores, foram simplesmente surpreendentes! Como se pode observar, na Turma A, o Gráfico 1 apontava 92\% dos alunos com médias abaixo de 5, o Gráfico 3 assinala que 95\% dos alunos tiraram nota acima de 5, sendo que todos os 39 alunos participaram da avaliação.

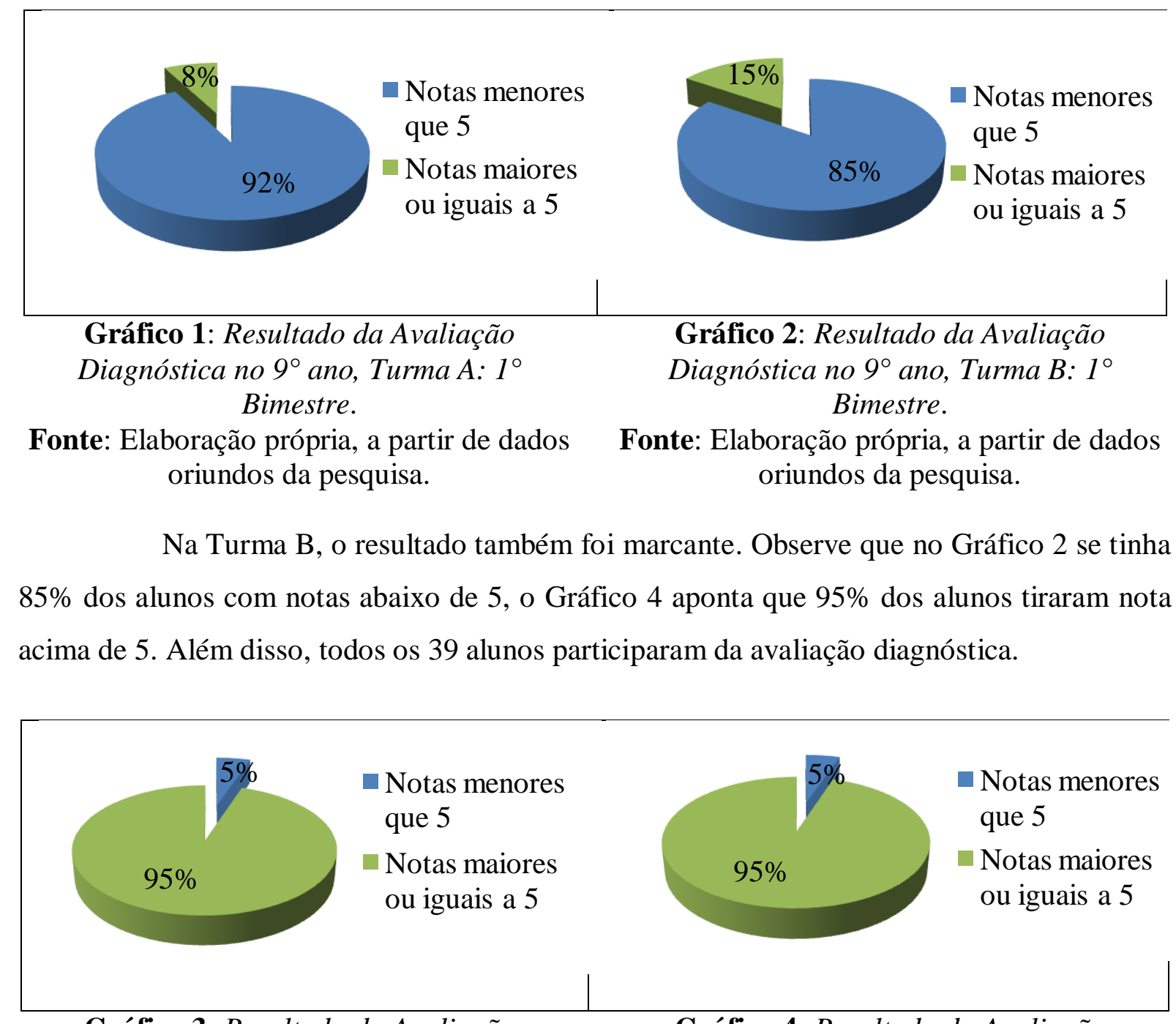

Gráfico 3: Resultado da Avaliação

Gráfico 4: Resultado da Avaliação 


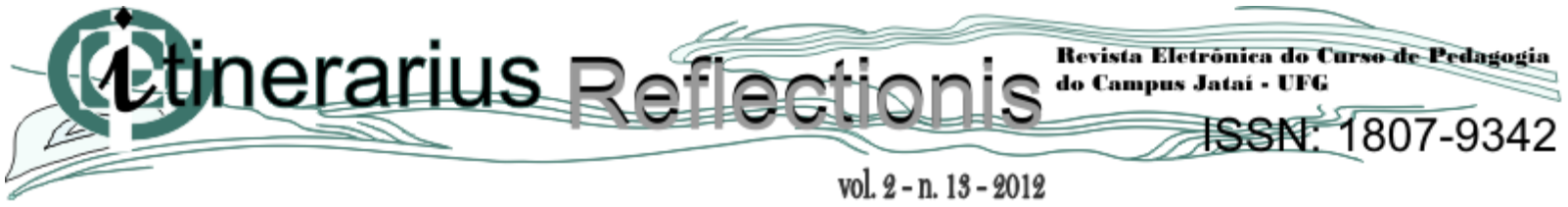

Diagnóstica no $9^{\circ}$ ano, Turma A: $2^{\circ}$

Bimestre.

Fonte: Elaboração própria, a partir de dados oriundos da pesquisa.
Diagnóstica no $9^{\circ}$ ano, Turma B: $2^{\circ}$

Bimestre.

Fonte: Elaboração própria, a partir de dados oriundos da pesquisa.

De uma forma geral, investigou-se o desempenho das turmas de $9^{\circ}$ ano engendradas neste projeto no processo seletivo do IFG, Câmpus Jataí. Foi solicitado junto à Coordenação de Registros Escolares e Acadêmicos (COREA) - IFG o desempenho desses alunos no processo seletivo 2012, nos Cursos Técnicos Integrados do Instituto Federal de Educação, Ciência e Tecnologia de Goiás e comparados este desempenho com os alunos que prestaram o processo seletivo no ano de 2011. Vale ressaltar que os alunos que participaram do processo seletivo de 2011 não possuíam acompanhamento, isto é, a monitoria. O resultado foi significativo e é registrado nos Gráficos 5 e 6.

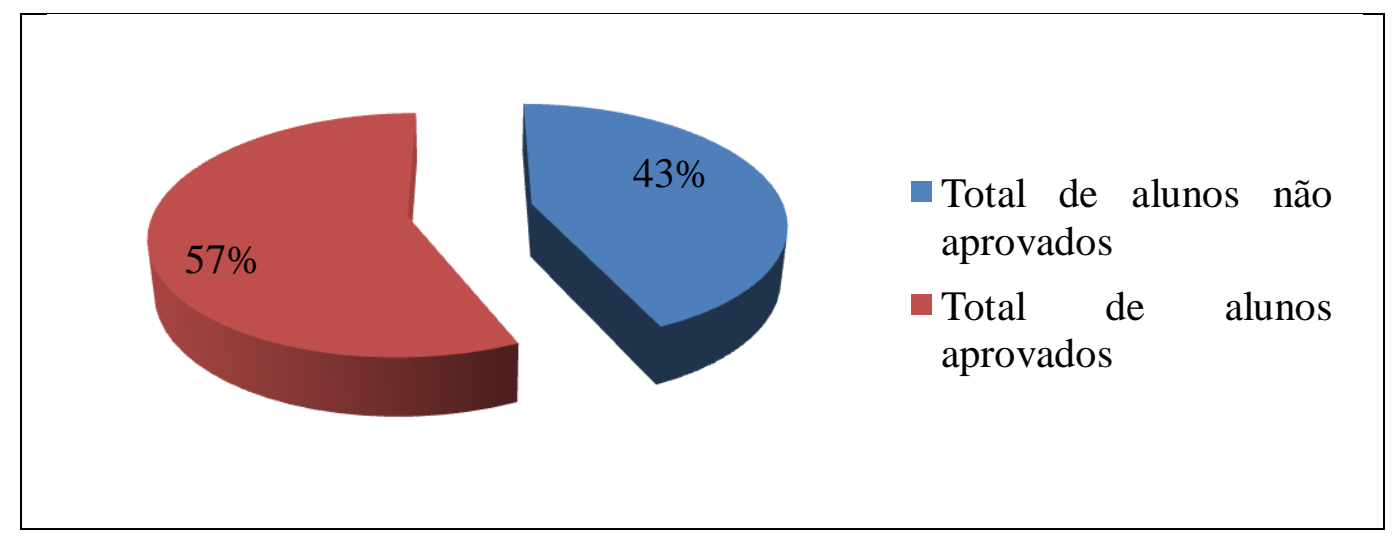

Gráfico 5: Percentual de alunos aprovados e reprovados no processo seletivo de 2012.

Fonte: Coordenação de Registros Escolares e Acadêmicos (COREA - IFG), Câmpus Jataí.

Percebe-se um salto de qualidade no que tange a aprovação desses alunos nos dois processos seletivos citados. Enquanto que em 2011 apenas $43 \%$ dos inscritos conseguiram aprovação, em 2012 este número salta para 62\%, significando um ganho percentual de 19\%. 

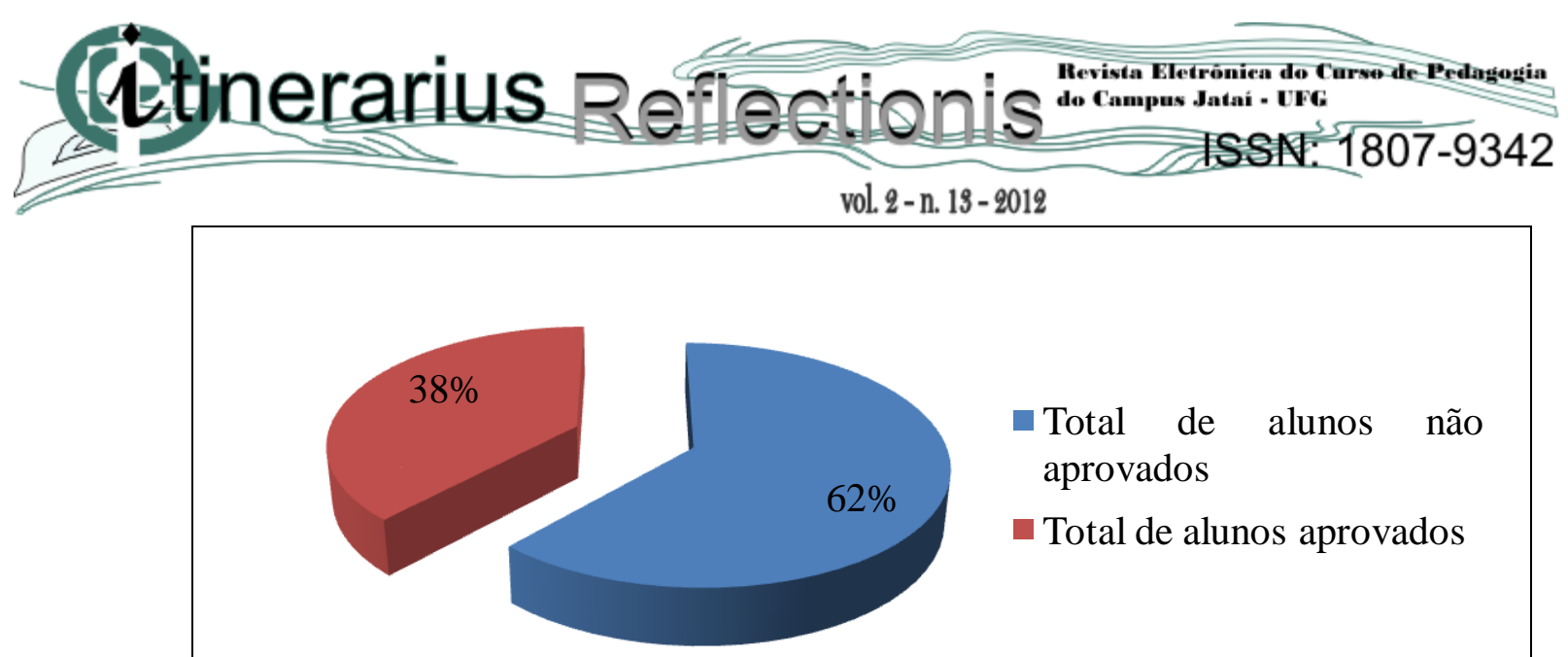

- Total de alunos não aprovados

- Total de alunos aprovados

Gráfico 6: Percentual de alunos aprovados e reprovados no processo seletivo de 2011.

Fonte: Coordenação de Registros Escolares e Acadêmicos (COREA - IFG), Campus Jataí.

Os dados ainda são mais surpreendentes se comparados com os resultados obtidos em nível Estadual. Estas informações podem ser visualizadas nos Gráficos 7 e 8 . As barras com as cores laranja, azul claro, verde e rosa representam respectivamente o desempenho dos alunos do Estado, Subsecretaria de Jataí, Município de Jataí e a Escola Estadual de Jataí onde o projeto de monitoria foi e está sendo realizado.

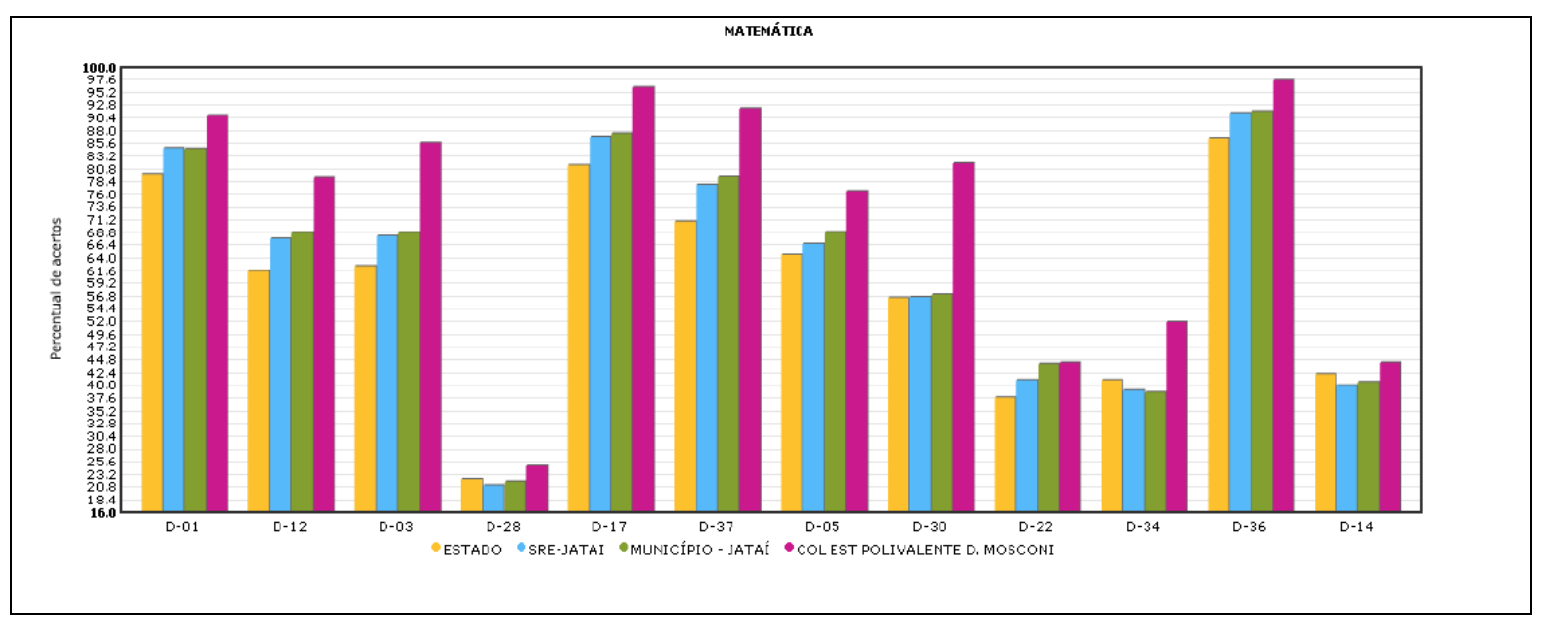

Gráfico 7: Desempenho na Avaliação Diagnóstica a Nível Estadual das Turmas A e B:2 ${ }^{\circ}$ Bimestre de 2011.

Fonte: Secretaria da Educação do Estado de Goiás.

Segue abaixo os descritores ponderados na Avaliação Diagnóstica do $2^{\circ}$ Bimestre. Eles são importantes, pois é através deles que se podem analisar o que exatamente cada aluno foi avaliado na Avaliação Diagnóstica do respectivo bimestre em questão. 


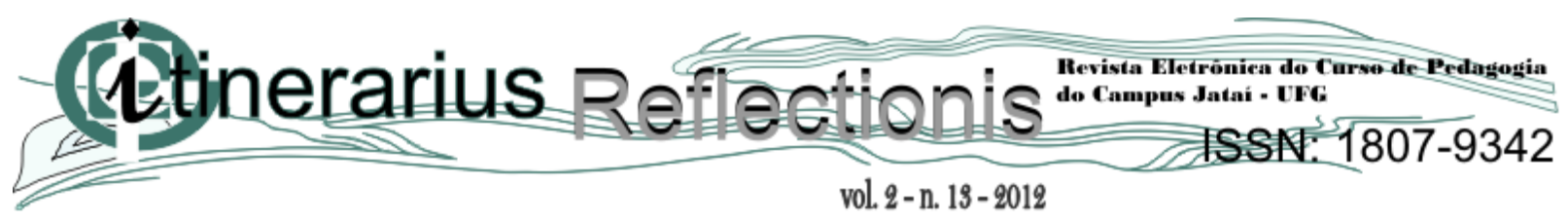

Tabela 1: Descritores analisados na segunda avaliação diagnóstica de 2011.

\begin{tabular}{l|l}
\hline & \multicolumn{1}{c}{ Legenda dos descritores } \\
\hline D-01 & $\begin{array}{l}\text { Identificar a localização/movimentação de objeto, em mapas, croquis e outras } \\
\text { representações gráficas. }\end{array}$ \\
\hline D-12 & Resolver problema envolvendo o cálculo de perímetro de figuras planas. \\
\hline D-03 & $\begin{array}{l}\text { Identificar propriedades de triângulos pela comparação de medidas de lados e } \\
\text { angulos. }\end{array}$ \\
\hline D-28 & Resolver problema que envolva porcentagem. \\
\hline D-17 & Identificar a localização de números racionais na reta numérica. \\
\hline D-37 & $\begin{array}{l}\text { Associar informações apresentadas em listas e/ou tabelas simples aos gráficos } \\
\text { que as representam e vice-versa. }\end{array}$ \\
\hline D-05 & $\begin{array}{l}\text { Reconhecer a conservação ou modificação de medidas dos lados, do perímetro, } \\
\text { da área em ampliação e/ou redução de figuras poligonais usando malhas } \\
\text { quadriculadas. }\end{array}$ \\
\hline D-30 & Calcular o valor numérico de uma expressão algébrica. \\
\hline D-22 & $\begin{array}{l}\text { Identificar fração como representação que pode estar associada a diferentes } \\
\text { significados. }\end{array}$ \\
\hline D-34 & $\begin{array}{l}\text { Identificar um sistema de equações do primeiro grau que expressa um } \\
\text { problema. }\end{array}$ \\
\hline D-36 & $\begin{array}{l}\text { Resolver problema envolvendo informações apresentadas em tabelas e/ou } \\
\text { gráficos. }\end{array}$ \\
\hline D-14 & Resolver problema envolvendo noções de volume. \\
\hline
\end{tabular}

Fonte: Secretaria da Educação do Estado de Goiás.

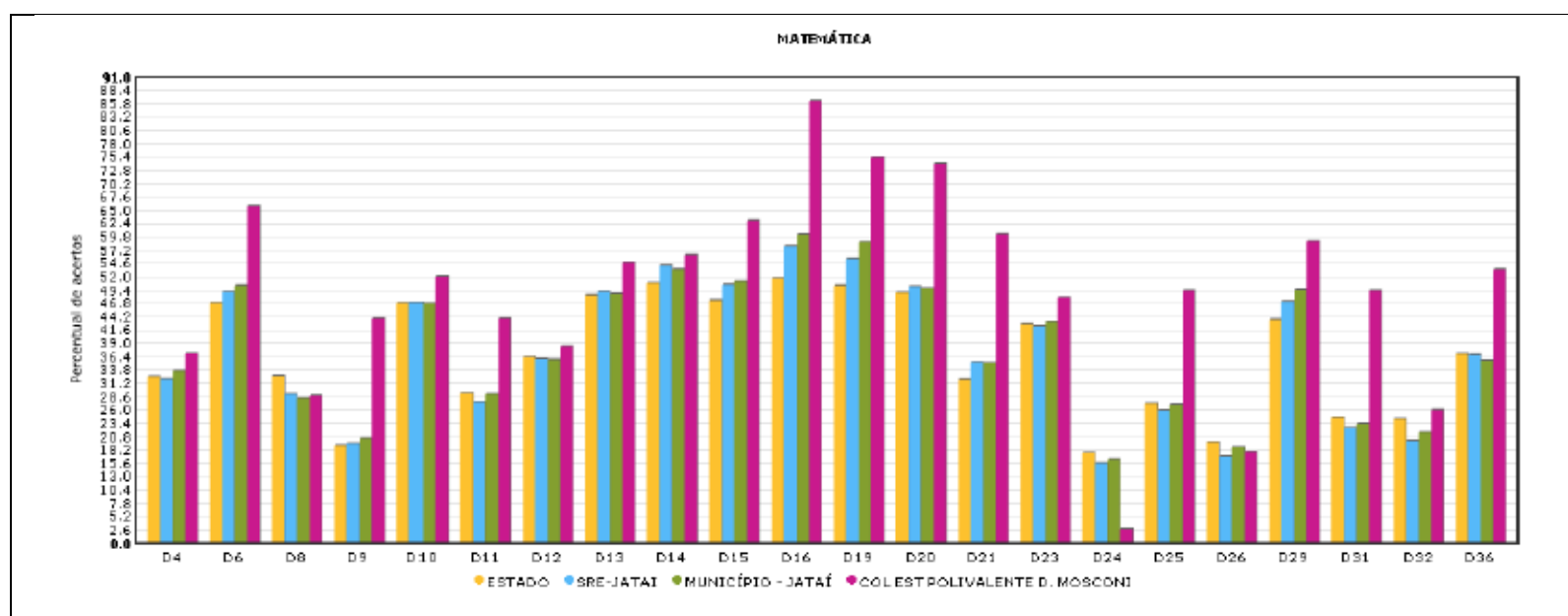

Gráfico 8: Desempenho na Avaliação Diagnóstica a Nível Estadual das Turmas A e B: $3^{\circ}$ Bimestre de 2011.

Fonte: Secretaria da Educação do Estado de Goiás. 


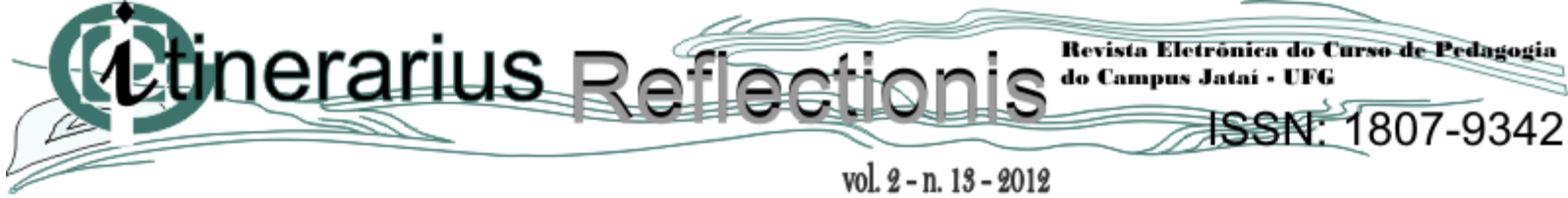

Observa-se que foram avaliados 12 descritores no segundo bimestre (ver Tabela 1) e 22 descritores no terceiro bimestre (ver Tabela 2). Percebe-se claramente uma melhor performance dos alunos da Escola Estadual de Jataí onde a monitoria foi e está sendo realizada, exceto no descritor 24 no Gráfico 8, que aborda representações decimais de números racionais.

Tabela 2: Descritores analisados na terceira avaliação diagnóstica de 2011.

\begin{tabular}{|c|c|}
\hline \multicolumn{2}{|r|}{ Legenda dos descritores } \\
\hline D-04 & Identificar relação entre quadriláteros, por meio de suas propriedades. \\
\hline D-06 & $\begin{array}{l}\text { Reconhecer ângulos como mudança de direção ou giros, identificando ângulos retos e } \\
\text { não-retos. }\end{array}$ \\
\hline D-08 & $\begin{array}{l}\text { Resolver problema utilizando a propriedade dos polígonos (soma de seus ângulos } \\
\text { internos, número de diagonais, cálculo da medida de cada ângulo interno nos } \\
\text { polígonos regulares). }\end{array}$ \\
\hline D-09 & Interpretar informações apresentadas por meio de coordenadas cartesianas. \\
\hline D-10 & $\begin{array}{l}\text { Utilizar relações métricas do triângulo retângulo para resolver problemas } \\
\text { significativos. }\end{array}$ \\
\hline D-11 & círculo/circunferência, seus elementos e algumas de suas relações. \\
\hline D-12 & olvendo \\
\hline D-13 & as. \\
\hline D-14 & Jivenu \\
\hline D-15 & \\
\hline D-16 & de nú \\
\hline D-19 & $\begin{array}{l}\text { a com números naturais envolvendo diferentes significados das } \\
\text { subtração, multiplicação, divisão e potenciação). }\end{array}$ \\
\hline D-20 & $\begin{array}{l}\text { Resolver problema com números inteiros envolvendo as operações (adição, } \\
\text { subtração, multiplicação, divisão e potenciação). }\end{array}$ \\
\hline D-21 & racional. \\
\hline $\mathrm{D}-23$ & entes. \\
\hline D-24 & $\begin{array}{l}\text { econhecer as representações decimais dos números racionais como uma extensão do } \\
\text { stema de numeração decimal identificando a existência de "ordens" como décimos. } \\
\text { ntésimos e milésimos. }\end{array}$ \\
\hline D-25 & $\begin{array}{l}\text { perações com números racionais (adição, subtração, } \\
\text { ão). }\end{array}$ \\
\hline D-26 & $\begin{array}{l}\text { Resolver problema com números racionais que envolvam as operações (adição, } \\
\text { subtração, multiplicação, divisão e potenciação). }\end{array}$ \\
\hline D-29 & $\begin{array}{l}\text { Resolver problema que envolva variações proporcionais, diretas ou inversas entre } \\
\text { grandezas. }\end{array}$ \\
\hline D-31 & Resolver problema que envolva equação de segundo grau. \\
\hline D-32 & $\begin{array}{l}\text { Identificar a expressão algébrica que expressa uma regularidade observada em } \\
\text { seqüências de números ou figuras (padrões). }\end{array}$ \\
\hline D-36 & \\
\hline
\end{tabular}




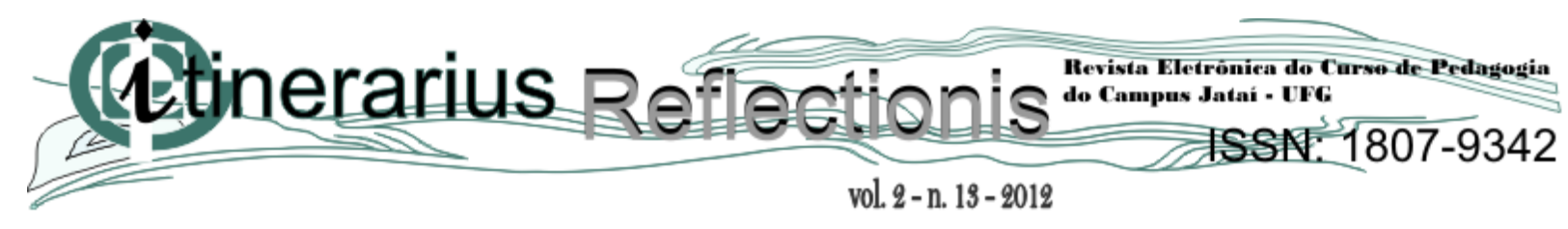

Fonte: Secretaria da Educação do Estado de Goiás.

\section{Considerações Finais}

Percebe-se nitidamente que o projeto de monitoria que foi e está sendo realizado em uma Escola estadual de Jataí foi importantíssimo no desempenho de seus alunos na Avaliação Diagnóstica de Goiás. Trata-se de um estudo de caso, porém certamente pode ser ampliado para todas as unidades de ensino deste país, através de incentivos do governo por meio de remuneração extra aos professores envolvidos, redução de carga horária ou até mesmo contratação de novos professores ou/e monitores, dentre outros. Por outro lado, o que se observa na maior parte das escolas do Brasil são professores entusiasmados com o que fazem e que na maioria das vezes concretizam seus projetos sem incentivo nenhum dos órgãos públicos, ou das escolas envolvidas. São educadores que executam suas atividades buscando apenas a satisfação profissional, em troca de um aluno mais crítico e sábio. Porém, isso não suficiente. Deve haver um compromisso de todas as instâncias governamentais, seja ela Municipal, Estadual ou Federal buscando encontrar soluções para os gargalos na educação. Um exemplo disso são os dados apresentados neste artigo. Eles são, sem dúvida, uma fonte de informações inquestionáveis e podem e devem ser usados como referência para futuros projetos por educadores ou até mesmo por órgãos públicos.

Para incorporar ainda mais esta pesquisa apresenta-se o Gráfico 9. Este mostra a média das notas obtidas pelos alunos no $1^{\circ}, 2^{\circ}$ e $3^{\circ}$ bimestres de 2011 .

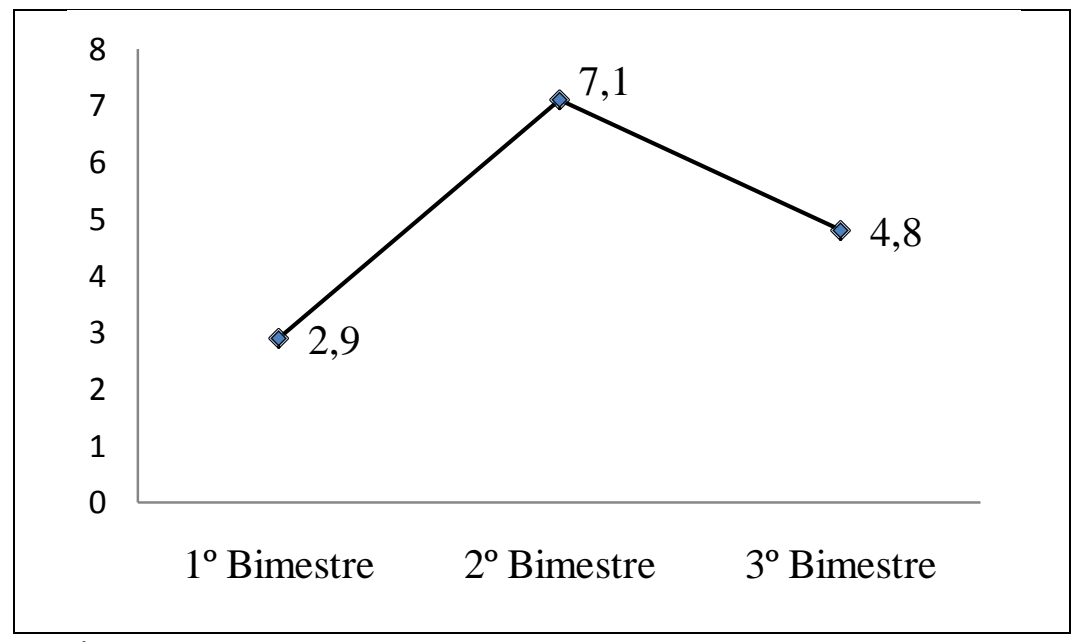

Gráfico 9: Média dos alunos no $1^{\circ}, 2^{\circ}$ e $3^{\circ}$ bimestres de 2011. 


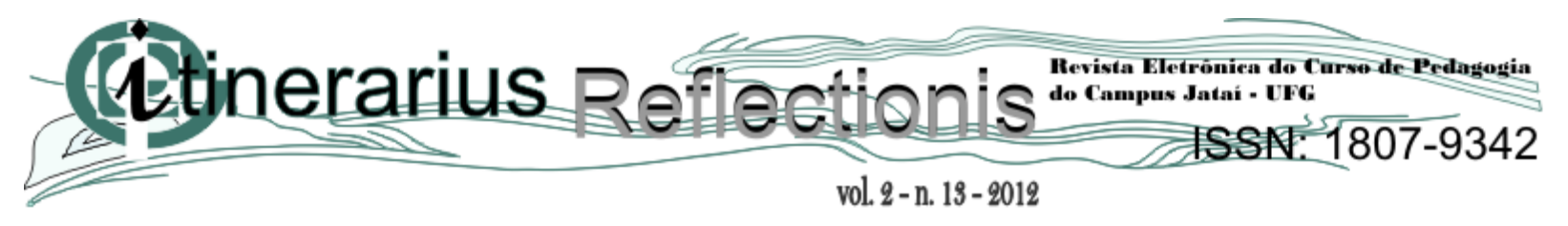

Fonte: Secretaria da Educação do Estado de Goiás.

Antes de analisar o Gráfico 9 deve-se fazer a seguinte ressalva: primeiramente, é importante enfatizar que no início do ano letivo de 2011 não existia nenhum acompanhamento desses alunos no formato do projeto que aqui foi apresentado. Observa-se que na primeira avaliação, as médias estavam muito aquém do esperado. A partir de março de 2011, com a implantação da monitoria, até o mês junho de 2011, quando foi aplicada a segunda avaliação diagnóstica, as médias saltaram de 2,9 para 7,1 da primeira para a segunda avaliação diagnóstica. Isso representa um aumento de aproximadamente 244,8\% nas médias apresentadas, o que é muito significativo e reforça a relevância dessa monitoria. Entretanto, a partir do final do mês de junho até o início do mês de agosto não houve monitoria devido às férias escolares do mês de julho e uma nova avaliação diagnóstica foi realizada no mês de setembro. Em suma, os alunos ficaram sem acompanhamento por aproximadamente 45 dias. As atividades de monitoria foram novamente estabelecidas na segunda quinzena de agosto. Percebeu-se um declínio nas médias de 7,1 para 4,8 da segunda para a terceira avaliação diagnóstica. Isso representa um decréscimo de aproximadamente $32,4 \%$ nas médias. $\mathrm{Na}$ verdade, isso que dizer que a monitoria deve ser um processo contínuo e ininterrupto, pois auxilia fortemente na aprendizagem dos alunos, não devendo ser obstruída. Por outro lado, deve-se enfatizar também que apesar das médias terem apresentado este declínio, a média da terceira avaliação ainda continua aproximadamente $65 \%$ maior que a média alcançada na primeira avaliação diagnóstica. Isto claramente representa um reflexo do que foi executado anteriormente no primeiro semestre de 2011 através da monitoria.

É importante destacar que além do bom desempenho nessas provas, esta monitoria colaborou não só para um desempenho melhor nestas avaliações diagnósticas, mas também, para um melhor desempenho dos mesmos na disciplina de Matemática durante o ano letivo de 2011.

Aliados ao bom desempenho dos alunos nestas avaliações deve-se destacar a mudança de hábitos dos discentes envolvidos nesta monitoria. Por exemplo, destaca-se o bom comportamento em sala aula, responsabilidade, respeito ao colega de classe e ainda reverência ao professor. Nuno e Rodrigues (2005) descrevem que a palavra "cidadania" quer dizer "1. Qualidade de cidadão; 2. Qualidade de uma pessoa que possui, em uma determinada 


\section{Etinerarius Refoctionis 20 \\ vol. $2-$ n. $13-2012$

comunidade política, o conjunto de direitos civis e políticos". Usando estas sábias palavras, pode-se finalizar este artigo afirmando que por meio do compromisso da equipe executora do projeto, através de seu coordenador e seus tutores, o comprometimento dos pais dos alunos envolvidos no processo, a equipe pedagógica da escola aliado a todos que de alguma forma colaboraram com este trabalho, conseguiu-se obter resultados simplesmente extraordinários tanto no que tange ao aprendizado quanto ao exercício da cidadania dos alunos que integram esta escola e participaram desta monitoria. Pois, por meio do conjunto de atividades desenvolvidas neste projeto, permitiu-se alcançar os patamares reservados aos alunos que em tese sempre deveriam ter na educação pública a excelência e qualidade, em todas as instâncias da escola, mas que em algum momento de sua trajetória escolar seus direitos garantidos na Constituição Federal não são respeitados, seja através de falta de infraestrutura, falta de recursos, por professores mal pagos ou sem qualificação específica.

\section{REFERÊNCIAS}

BRASIL. Ministério da Educação. Ideb. Educação. 2011. Disponível em: <http://portal.mec.gov.br/index.php?Itemid=336\&id=180\&option=com_content\&view=articl e>. Acesso em: 10 nov. 2011.

CARVALHO, José Murilo. Cidadania no Brasil: O longo Caminho. 3. ed. Rio de Janeiro: Civilização Brasileira, 2002.

DALLARI, Dalmo de Abreu. Direitos Humanos e cidadania. 1.ed. São Paulo: Moderna, 1998.

D’AMBRÓSIO, Ubiratan. Etnomatemática - elo entre as tradições e a modernidade. São Paulo: Ática. 1990.

FERREIRA, Raquel. Alunos encontrarão escolas sucateadas. 2012. Disponível em: <http://www.gazetadigital.com.br/conteudo/show/secao/9/materia/312060>. Acesso em: 05 maio 2012.

GAMA, Cláudio Márcio Araújo da. Administração pública: Políticas públicas sobre a educação no Brasil. 2008. Disponível em: <http://www.administradores.com.br/informese/artigos/administracao-publica-politicas-publicas-sobre-a-educacao-no-brasil/23101/>.

Acesso em: 25 dez. 2012.

GIL, Antônio Carlos. Métodos e técnicas de pesquisa social. 5.ed. São Paulo: Atlas. 1999. 
GOIÁS. Secretaria da Educação do Estado de Goiás. Arquivos. Educação. Disponível em: <http://www.see.go.gov.br/imprensa/documentos/>. 2011a. Acesso em: 10 nov. 2011.

\author{
—. Secretaria da Educação do Estado de Goiás. Avaliação diagnóstica da rede pública \\ estadual é independente do Ideb. 2011b. Disponível em: \\ <http://www.educacao.go.gov.br/imprensa/?Noticia=2620>. Acesso em: 05 ago. 2011.
}

MENDONÇA, Valquíria Lúcia de Melo. Novos modos de subjetivação e cidadania: uma articulação necessária. 2006. 85 f. Dissertação (Mestre) - Curso de Programa de Pósgraduação em Psicologia, Departamento de Psicologia, Pontifica Universidade Católica de Minas, Belo Horizonte, $2006 . \quad$ Disponível em: <http://www.pucminas.br/documentos/dissertacoes_valquiria_mendonca.pdf $>$. Acesso em: 10 nov. 2011.

MOÇO, Anderson. A Prova Brasil em detalhes. Disponível em: $<$ http://revistaescola.abril.com.br/planejamento-e-avaliacao/avaliacao/prova-brasil-detalhes450869.shtml>. Acesso em: 10 nov. 2011.

NUNO, Fernando; RODRIGUES, Diego. Mini Larousse: Dicionário da Língua Portuguesa. 1. ed. São Paulo: Larousse do Brasil. 2005.

PINHO, Ângela. (Brasília). Brasil fica no $88^{\circ}$ lugar em ranking de educação da Unesco. Educação. 2011. Disponível em: <http://www1.folha.uol.com.br/saber/882676brasil-fica-no-88-lugar-em-ranking-de-educacao-da-unesco.shtml>. Acesso em: 05 ago. 2011.

PINSKY, Jaime; PINSKY, Carla Bassanezi. História da Cidadania. 2. ed. São Paulo: Contexto, 2003.

PONTE, João Pedro da. Estudos de Caso em Educação Matemática. Bolema: Boletim de Educação Matemática, São Paulo, v. 19, n. 25, p.1-23, 2006. Semestral. Disponível em: <http://www.periodicos.rc.biblioteca.unesp.br/index.php/bolema/article/view/1880/1657>.

Acesso em: 26 dez. 2012.

SANTOS, Aldelei Aluisio dos. Concepções Contemporâneas de Educação: Pedagogia Tradicional. 2010. Disponível em: <http://www.webartigos.com/artigos/pedagogiatradicional/52673/>. Acesso em: $28 \mathrm{dez} .2012$.

SANTOS, Milton. As Cidadanias Mutiladas. In: Preconceito. São Paulo: Secretaria da Justiça e da defesa da Cidadania do Estado de São Paulo, 1997.

SIEGEL, Norberto. Fundamentos da Educação: Temas Transversais e Ética. 1. ed. Blumenau: Grupo Uniasselvi. 2005.

VILLELA, Viviane Merlim Moraes. O conceito de cidadania nas definições de políticas públicas educacionais. Debates e impasses no processo de elaboração do Plano Municipal de 


\section{Ctinerarius Reflectionis 201}

Educação de Niterói/RJ. 2008. 246 f. Dissertação (Mestre) - Curso de Pós-graduação em Educação, Departamento de Educação, Universidade Federal Fluminense, Rio de Janeiro, 2008. Disponível em:

<http://www.uff.br/pos_educacao/joomla/images/stories/Teses/viviane.pdf >. Acesso em: 10 nov. 2011.

VYGOTSKY, Lev Semenovich. A formação social da mente: o desenvolvimento dos processos psicológicos superiores. Tradução de José Cipolla Neto, Luis Silveira Menna Barreto, Solange Castro Afeche. $4^{\mathrm{a}}$ ed. São Paulo - SP: Livraria Martins Fontes Editora Ltda. 1991. Disponível em:

$<$ http://chafic.com.br/chafic/moodle/file.php/1/Biblioteca_Virtual/Temas_educacionais/Lev._ Vygotsky_-_A_formacao_social_da_mente.pdf >. Acesso em: 28 dez. 2012. 